\title{
Correlación del potencial óxido reducción y la población bacteriana durante el estudio de biolixiviación de sulfuros de cobre
}

\author{
Correlation of the oxide reduction potential and the bacterial population during \\ the study copper sulphide bioleaching \\ Vladimir Alejandro Arias Arce 1, Daniel Florencio Lovera Dávila ${ }^{2}$, \\ Abad Flores Paucarima ${ }^{3}$, Tito Libio Sánchez Rojas ${ }^{4}$
}

Recibido: 15/02/2021 - Aprobado: 21/04/2021 - Publicado: 18/06/2021

\begin{abstract}
RESUMEN
Se estudio la correlación de las variables población bacteriana y potencial de óxido reducción (ORP) en la biolixiviación de minerales sulfurados mediante cepa bacteriana de Acidithiobacilus Ferrooxidans aisladas a partir de efluente ácido de mina, buscando la solubilización del cobre y la liberación del oro presente en un mineral con sulfuros superior a 80\%. Las variables de experimentación fueron: La densidad de pulpa a 1, 2 y $6 \%$ (W/V), concentración de sulfato ferroso como parte del medio $9 \mathrm{k}$ de 0, 3, 6, 9 y $15 \mathrm{gr} / \mathrm{L}$; manteniendo constante la temperatura, agitación del medio y el pH. Los ensayos se realizaron en tres etapas consecutivas, iniciándose con inoculo conteniendo $7.05 \times 10^{7} \mathrm{Cel} / \mathrm{mL}$ y luego, la obtenida en cada etapa previa, observándose la variación en los periodos de adaptación y crecimiento. En la primera etapa la máxima población bacteriana alcanzada fue de $4.75 \times 10^{7} \mathrm{Cel} / \mathrm{mL}$ en 24 días con $6 \mathrm{~g} / \mathrm{L}$ de sulfato ferroso. En la segunda etapa se obtuvo una máxima densidad de $6.30 \times 10^{7} \mathrm{Cel} / \mathrm{mL}$ sin la adición de sulfato ferroso. En la tercera etapa la densidad bacteriana alcanzada fue de $4.51 \times 10^{7} \mathrm{Cel} / \mathrm{mL}$., con inicios de crecimiento exponencial aproximadamente a los 13, 8 y 3 días, respectivamente. Las cepas bacterianas fueron adaptadas satisfactoriamente en distintos medios conteniendo cantidades variadas de hierro y minerales sulfurados, dando mejores resultados sin la adición de sulfato ferroso.
\end{abstract}

Palabras Clave: Potencial óxido reducción; población bacteriana; Biolixiviación; sulfuros de cobre; adaptación de acidithiobacillus.

\begin{abstract}
The correlactionship of bacterial population and oxidation-reduction potential in the bioleaching of sulfuric minerals by bacterial strain of Aciditiobacilus Ferrooxidans isolated from acid mine effluent was studied. The solubilization of copper and gold release from a mineral with sulphides exceeding $80 \%$ was evaluated. The experimental variables were: Pulp density at 1, 2 and $6 \%(W / V)$, concentration of ferrous sulfate as part of the $9 \mathrm{k}$ medium of $0,3,6,9$ and $15 \mathrm{gr} / \mathrm{L}$.; maintaining constant temperature and $\mathrm{pH}$. The tests were carried out in three consecutive stages, starting with inoculum containing $7.05 \times 10^{7} \mathrm{Cell} / \mathrm{mL}$ and then the one obtained in each previous stage, observing the variation in the periods of adaptation and growth. In the first stage the maximum bacterial density reached in 24 days was $4.75 \times 10^{7} \mathrm{Cell} / \mathrm{mL}$ with $6 \mathrm{~g} / \mathrm{L}$ of ferrous sulfate. In the second stage a maximum density of $6.30 \times 10^{7}$ Cell/mL was obtained without the addition of ferrous sulfate. In the third stage the bacterial density reached $4.51 \times 10^{7} \mathrm{Cell} / \mathrm{mL}$, with exponential growth starts at approximately 13,8 and 3 days, respectively. Bacterial strains are successfully adapted in different media containing varying amounts of iron and sulfuric minerals, regardless of iron sulfate as part of the bacterial substrat.
\end{abstract}

Keywords: Oxidation-reduction potential; bacterial population; bioleaching; copper sulfides; Acidithiobacillus adaptation.

1 Grupo de Investigaciones en Medioambiente y Biometalurgia. Universidad Nacional Mayor de San Marcos, Facultad de Ingeniería Geológica, Minera, Metalúrgica y Geográfica, Departamento de Ingeniería Metalúrgica. Lima, Perú. E-mail: variasa@unmsm.edu.pe - ORCID: https://orcid.org/0000-0002-7053-9656

2 Departamento de Ingeniería Metalúrgica. Universidad Nacional Mayor de San Marcos, Facultad de Ingeniería Geológica, Minera, Metalúrgica y Geográfica. Lima, Perú. E-mail: dloverad@umsm.edu.pe - ORCID: https://orcid.org/0000-0003-2815-0716

3 Universidad Nacional Mayor de San Marcos, Facultad de Biología, Departamento de Microbiología y Biotecnología. Lima, Perú. E-mail: afloresp@unmsm.edu.pe - ORCID: https://orcid.org/0000-0002-7657-3687

4 Universidad Nacional Mayor de San Marcos, Facultad de Biología, Departamento de Microbiología y Biotecnología. Lima, Perú. E-mail: tsanchezr@unmsm.edu.pe - ORCID: https://orcid.org/0000-0003-3853-2128 


\section{INTRODUCCIÓN}

El potencial redox es una medida de la actividad de los electrones, como el $\mathrm{pH}$ es la medida de la actividad de los protones, por lo tanto, la identificación del potencial de óxido-reducción (ORP), es un factor crítico en el desarrollo del inóculo y en la evolución de la oxidación de los compuestos inorgánicos, se determina con un electrodo de referencia de platino y un electrodo de hidrógeno conectado a un potenciómetro. Se cuantifica en voltios, que representa la energía liberada por todos los componentes en una fracción de tiempo cuando un número de electrones viajan desde una fase a otra; específicamente, entre el sustrato de biolixiviación y el electrodo de platino.

La oxidación biológica del sulfuro a azufre, sulfato y otros compuestos azufrados y la reducción del oxígeno en agua representan los principales cambios redox que ocurren en este proceso. La medición del valor ORP de estará determinada por el conjunto de las reacciones.

Similarmente, la relación termodinámica del ORP representado por el Eh de acuerdo a la composición de la solución es generalmente conocida como la ecuación de Nernst, sin embargo en la práctica el valor del ORP está determinado principalmente, por los compuestos iónicos de alta densidad de intercambio de corriente, es decir la habilidad que tienen para intercambiar electrones en la superficie del electrodo de platino; en este sentido, varios autores revelan que existen compuestos que tienen alta capacidad de intercambiar sus electrones de valencia en la superficie de platino, tal es el caso de sulfuro de hidrógeno, para el cual existe una relación lineal entre la medida ORP y el logaritmo de la concentración del sulfuro de hidrógeno en ambientes naturales (Fagundo C. et al., 2005).

La utilidad de los datos de ORP puede ser cuestionable porque la sonda de medición está directamente en contacto con el seno del ambiente extracelular el cual es totalmente diferente del ambiente intracelular. Una desventaja del ORP es su fuerte dependencia del $\mathrm{pH}$. Al respecto, se han reportado decrementos en el ORP de $33 \mathrm{mV}$ con el incremento en una unidad en el pH (Alvarez, 2009).

Se tiene conocimiento que, en los medios de cultivo los microorganismos presentan sensibilidad muy variada al potencial de óxido reducción. Por ello se cree que el potencial redox es un factor muy particular e importante en cada uno de los ambientes donde el sustrato probablemente determina la presencia de una variedad de microorganismos y en su evolución metabólica (Kaksonen et al., 2004).

\section{MÉTODOS}

\subsection{Antecedentes de los bioprocesos}

En años recientes el desarrollo de procesos microbiológicos para la extracción de los metales desde cuerpos mineralizados ha generado mucho interés y el acercamiento a los procesos de biotecnológicos como la biooxidación, que ya se aplican en muchas partes del mundo. Son las razones fundamentales para la investigación y para otorgar estímulos a los nuevos descubrimientos y; además, probablemente se convierta en la causa del desarrollo del sector minero metalúrgico (Sand et al., 1995; (Donati \& Sand, 2007).

Se puede aseverar que las fuentes donadoras de electrones son abundantes y diversas en la naturaleza $\mathrm{y}$, estos pueden ser de origen antropogénico, geológico y biológico, en común de materiales inorgánicos. Una importante fuente de compuestos inorgánicos es la actividad volcánica; como compuestos reducidos de azufre y otros. Todos los compuestos derivados de la industria minera y la agrícola, productos de la quema de hidrocarburos y de otras actividades industriales que liberan al medio ambiente compuestos reducidos de azufre, los efectúan labor de donar o recibir electrones y por ende energía mediante bacterias quimiolitoautótrofas sulfoxidantes (Espinoza et al., 2010).

Durante las tres últimas décadas, la aplicación de la biolixiviación para el tratamiento de los minerales sulfurados de cobre ha alcanzado su industrialización, el uso secuencial de la biooxidación - biolixiviación electrodeposición, para la extracción de uranio, oro y zinc, ha dado y sigue brindando satisfacción en el sector minero. Además, en los últimos años se está buscando su aplicación para la extracción de cobre a partir de minerales llamados refractarios (Wang et al., 2014).

\subsection{Procedimiento experimental}

El diseño experimental, su implementación y ejecución de los ensayos, se efectuó en el Laboratorio de Biometalurgia de la Escuela de Ingeniería Metalúrgica, con participación de docentes y estudiantes de las facultades de: Química e Ingeniería Química y Ciencias Biológicas.

Se efectuaron mediciones del potencial (Ev) y determinaciones de la población bacteriana a distintas concentraciones de sustrato, manteniendo constantes $\mathrm{pH}$, temperatura y agitación. El medio de ensayo se conformó de mineral sulfurado, $100 \mathrm{~mL}$ de solución $9 \mathrm{k}, 10 \mathrm{ml}$ de inóculo y a $\mathrm{pH} 1.8$, temperatura ambiental promedio de $22^{\circ} \mathrm{C}$ y con agitación constante de $150 \mathrm{RPM}$

Los análisis químicos se realizaron en el laboratorio de Análisis Químico de la Escuela de Ingeniería Metalúrgica, los análisis de Absorción Atómica y por Espectrometría de plasma Inducido, se realizaron por servicio de terceros. El recuento de población bacteriana se realizó en el laboratorio de Microbiología Ambiental y Biotecnología de la Facultad de Ciencias Biológicas, UNMSM.

\subsubsection{Materiales}

Un aspecto importante del mineral tratado es su naturaleza, con contenidos diversos de sulfuros, siendo de interés los sulfuros de cobre. El mineral sulfurado fue triturado a malla -200 al 94\%, permitiéndose la oxidación y la provisión de nutrientes para el crecimiento de los microorganismos.

\subsubsection{Inóculo de Acidithiobacilus Ferrooxidans}

El inóculo de $7.05 \times 10^{7}$ Cell $/ \mathrm{mL}$., se obtuvo luego de un proceso de aislamiento y adaptación a partir de un drenaje ácido de mina, de antiguas labores mineras en la región 
de Huancavelica, Perú. Los medios de cultivo que se utilizaron nos permitieron aislar y concentrar la bacteria y su identificación se realizó mediante la técnica de reacción en cadena de la polimerasa (PCR) brindando 98\% de probabilidad en la identificación (Arias et al., 2015).

\subsubsection{Sustrato mineral como medio metabólico}

La composición mineralógica del mineral sulfurado que forma parte del sustrato en la biolixiviación fue identificada, conteniendo tenores de cobre, oro y plata. Así como alto contenido de ganga con compuestos sulfurados que incrementará el $\mathrm{pH}$ en el licor de lixiviación, con la consiguiente inhibición y supresión de la actividad microbiana (Barton et al., 2010). El grado de lixiviación también depende del tipo de superficie del sustrato mineral, es así como la disminución de tamaño de partícula significa un incremento de superficie específica, de modo que los rendimientos en disolución u oxidación pueden ser obtenidos sin ninguna alteración de la masa total de las partículas. Es considerado tamaño optimo, partículas de aproximadamente $42 \mu \mathrm{m}$ (Arias et al., 2015). Adicionalmente la provisión de un caldo de cultivo $9 \mathrm{k}$ modificado en su contenido de sal ferrosa, favorece la reactividad del medio (Acevedo, F., Gentina, 2005).

\subsection{Método operativo}

Los primeros ensayos realizados correspondieron al análisis químico de identificación por elementos, cuyos resultados fueron sometidos al análisis teórico basado en la información bibliográfica, con la finalidad de definir los parámetros operativos a utilizar en los ensayos. Conociéndose que en ensayos de biolixiviación por un periodo prolongado de 60 días se logra mantener la población bacteriana alrededor del 550-590 mV (Rivera et al., 2011). Además, la evolución de la población bacteriano muestra incrementos en cierto periodo de tiempo, como es entre los 6 y 21 días de proceso, la población bacteriana promedio fue de $1,70 \times 10^{8} \mathrm{cel} / \mathrm{mL}$ y de $8,00 \times 10^{7} \mathrm{cel} / \mathrm{mL}$ en la biolixiviación de mineral cuyas granulometrías correspondían a las mallas Tyler -200 y -325 , respectivamente (Ospina et al., 2012).

\subsection{Plan de trabajo}

En el presente trabajo de investigación tipo exploratoria, se determinó la realización de 3 etapas consecutivas, en función a los resultados previos de cada una precedente. Las condiciones operativas en detalle se muestran en la Figura 1.

\section{ENSAYOS DE BIOLIXIVIACIÓN}

El ensayo previo de biolixiviación se realizó en frascos Erlenmeyer de $250 \mathrm{~mL}$ y, en 3 periodos secuenciales con $1.0,2.0$ y $6.0 \%(\mathrm{~W} / \mathrm{V})$ de mineral sulfurado, se provee como sustrato nutriente, solución de la formulación $9 \mathrm{k}$ en distintas concentraciones de sulfato ferroso. Durante los ensayos, se realizan mediciones de potencial óxido

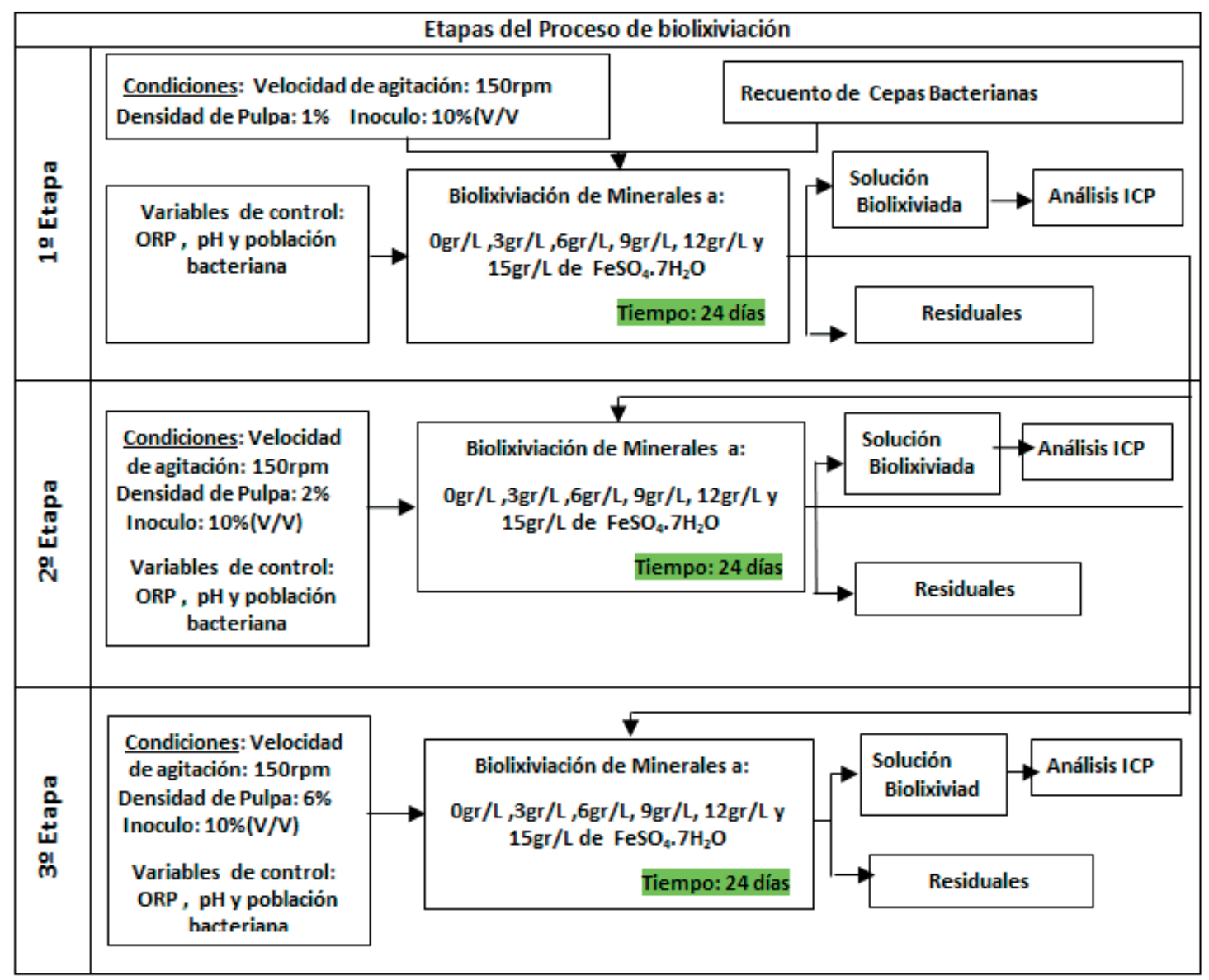

Figura 1. Etapas del proceso de biolixiviación con 1,2 y $6 \%$ de densidad de pulpa. 
reducción (ORP) y pH; además, se efectúan muestreos periódicos para la determinación de los metales presentes, como cobre, hierro, arsénico y zinc.

\subsection{Primera etapa de biolixiviación}

La solución de biolixiviación tenía como principal sustrato nutriente el Medio 9k a diferentes concentraciones de $\mathrm{FeSO}_{4} \cdot 7 \mathrm{H}_{2} \mathrm{O}$ entre 0.0 a $15.0 \mathrm{~g} / \mathrm{L}$. Para los ensayes se utilizaron frascos Erlenmeyer de $500 \mathrm{~mL}$, donde se agregó $3 \mathrm{~g}$ de mineral $(1 \% \mathrm{~W} / \mathrm{V}), 30 \mathrm{~mL}$ de cepa bacterial de $7.05 \times 10^{7} \mathrm{Cell} / \mathrm{mL}$ y $300 \mathrm{~mL}$ de solución $9 \mathrm{k}$ conteniendo: 3.0, 6.0, 9.0, 12.0 y $15.0 \mathrm{~g} / \mathrm{L}$ de $\mathrm{FeSO}_{4} \cdot 7 \mathrm{H}_{2} \mathrm{O}$. se reguló el pH a 1.8 adicionando solución de ácido sulfúrico. Realizándose el proceso en plataforma de agitación (Orbit Shaker) a $150 \mathrm{rpm}$. Según investigaciones, la dosis de iones ferroso para la biolixiviación de los sulfuros como la pirita y la calcopirita, difieren en función a las características del mineral que los contiene (Pradhan et al., 2008).

\section{bacteriana.}

\subsubsection{Efecto en el crecimiento de población}

Durante la biolixiviación el crecimiento bacteriano fue identificado en función al contenido de la sal férrica, observándose incremento acelerado entre el 12vo. y el 24vo. día y luego se produce el quiebre indicando la finalización de la etapa de crecimiento de la población bacteriana. La máxima densidad poblacional alcanzada fue a los 24 días con $4.75 \times 10^{7} \mathrm{Cell} / \mathrm{mL}$ con $6.0 \mathrm{~g} / \mathrm{L}$ de $\mathrm{FeSO}_{4} .7 \mathrm{H}_{2} \mathrm{O}$ llegando al $67 \%$ del inoculo, tal como se muestra en la Figura 2.
La metodología empleada en los procesos de biolixiviación, toma en cuenta la etapa de adaptación, ésta es progresiva de la bacteria $A$. ferrooxidans en presencia de iones nutrientes (Arias et al., 2015), donde se logra la reproducción de los microorganismos; paralelamente, se incrementan los compuestos metálicos en solución (Rawlings, 2005, Ospina et al., 2012).

\subsubsection{Variación del $p H$}

Las pruebas se inician con $\mathrm{pH}$ de $1.8 \mathrm{y}$, a diferentes concentraciones de $\mathrm{FeSO}_{4} \cdot 7 \mathrm{H}_{2} \mathrm{O}$. Durante el periodo de la primera etapa que tiene una duración de 19 días, se observa y regula la variación. El pH varía desde un mínimo de 1.6 a un máximo de 2.1, en promedio 1.9. Finalmente, la tendencia es descendente, probablemente por la aparición de $\mathrm{H}^{+}$y la formación de ácido sulfúrico, la que se puede apreciar en la Figura 3.

\subsubsection{Medición del potencial de óxido-reducción}

En la figura 4 se muestran valores de ORP para cada ensayo realizado, en los primeros 6 días la muestra que contiene $0.0 \mathrm{~g} / \mathrm{L}$ de $\mathrm{FeSO}_{4} \cdot 7 \mathrm{H}_{2} \mathrm{O}$ se incrementa de 360 $\mathrm{mV}$ hasta $585 \mathrm{mV}$ al décimo día. Por otro lado, la muestra que contiene $15.0 \mathrm{~g} / \mathrm{L}$ de $\mathrm{FeSO}_{4} \cdot 7 \mathrm{H}_{2} \mathrm{O}$ logra incremento aproximadamente, después de 10 días iniciada, hasta llegar al máximo $560 \mathrm{mV}$. Posteriormente, todas las muestras se mantienen alrededor de $575 \mathrm{mV}$.

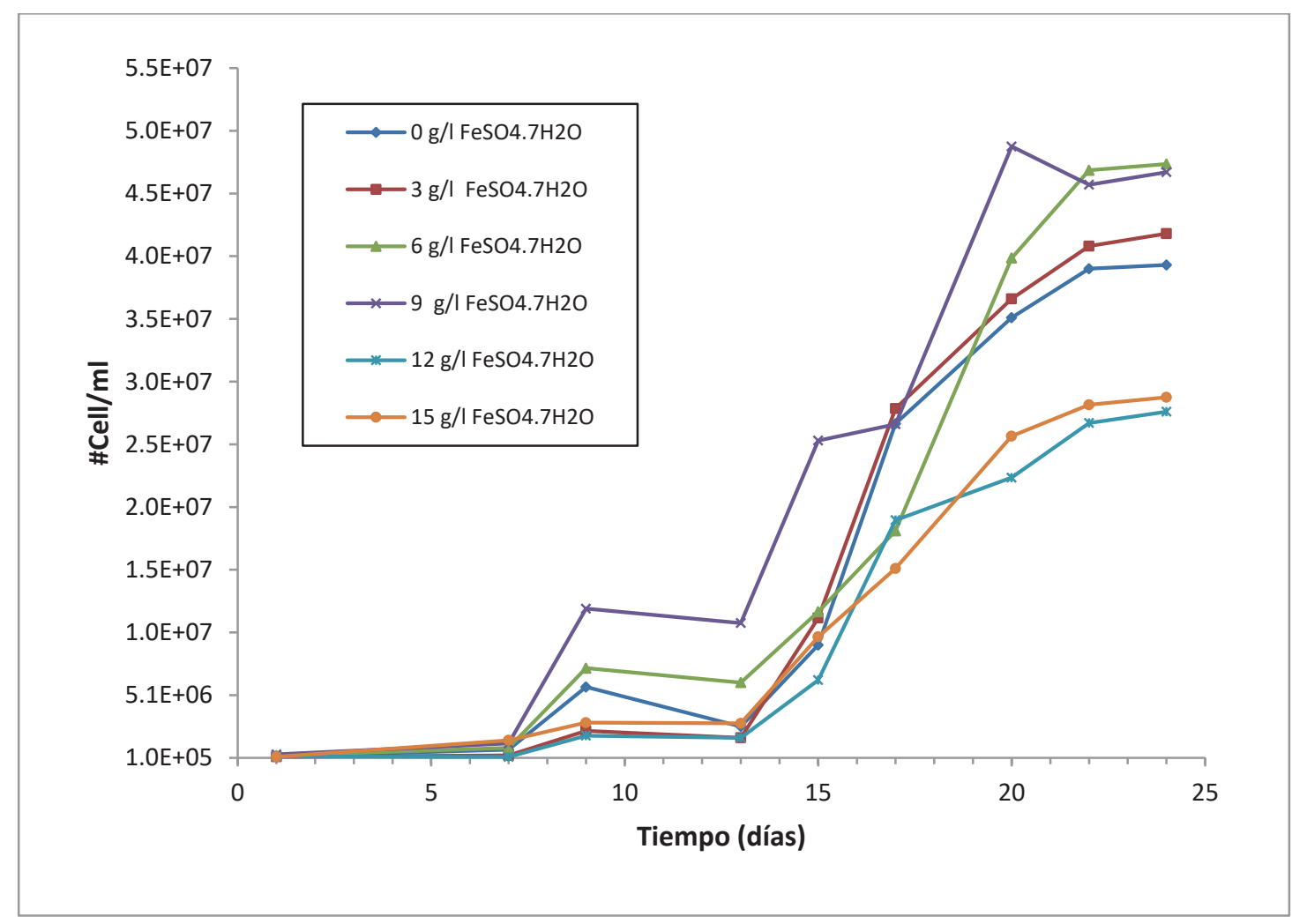

Figura 2. Variación de la población bacteriana durante la primera etapa de biolixiviación de un mineral sulfurado. 
La máxima recuperación de cobre obtenida en esta etapa fue de $72.64 \%$, con $6.0 \mathrm{~g} / \mathrm{L}$ de $\mathrm{FeSO}_{4} .7 \mathrm{H}_{2} \mathrm{O}$ y la recuperación mínima fue de $30.96 \%$ con $15.0 \mathrm{~g} / \mathrm{L}$ de FeSO ${ }_{4} 7 \mathrm{H}_{2} \mathrm{O}$. Después de aproximadamente 20 días de iniciado el proceso, se observa que la recuperación de cobre se detiene.

\subsection{Segunda etapa de Biolixiviación}

Los ensayos se realizaron en frascos Erlemeyer de 500 $\mathrm{mL}$, adicionando $18.0 \mathrm{~g}$ de mineral $(6 \% \mathrm{~W} / \mathrm{V}), 30 \mathrm{~mL}$ de cepa bacteriana $(10 \% \mathrm{~V} / \mathrm{V})$ y $300 \mathrm{~mL}$ de Medio $9 \mathrm{k}$ con $\mathrm{FeSO}_{4} .7 \mathrm{H}_{2} \mathrm{O}$ equivalentes a $0.0,2.0,4.0$ y $6.0 \mathrm{~g} / \mathrm{L}$. El pH es regulado a 1.9 con solución de ácido sulfúrico, se continuó el proceso en una plataforma de agitación a $150 \mathrm{rpm}$. Se utiliza cepa bacteriana proveniente de la primera etapa.

\subsubsection{Efecto en el crecimiento bacteriano}

La Figura 5 muestra el incremento de la densidad microbiana. Habiendo tomado como inoculo cuya

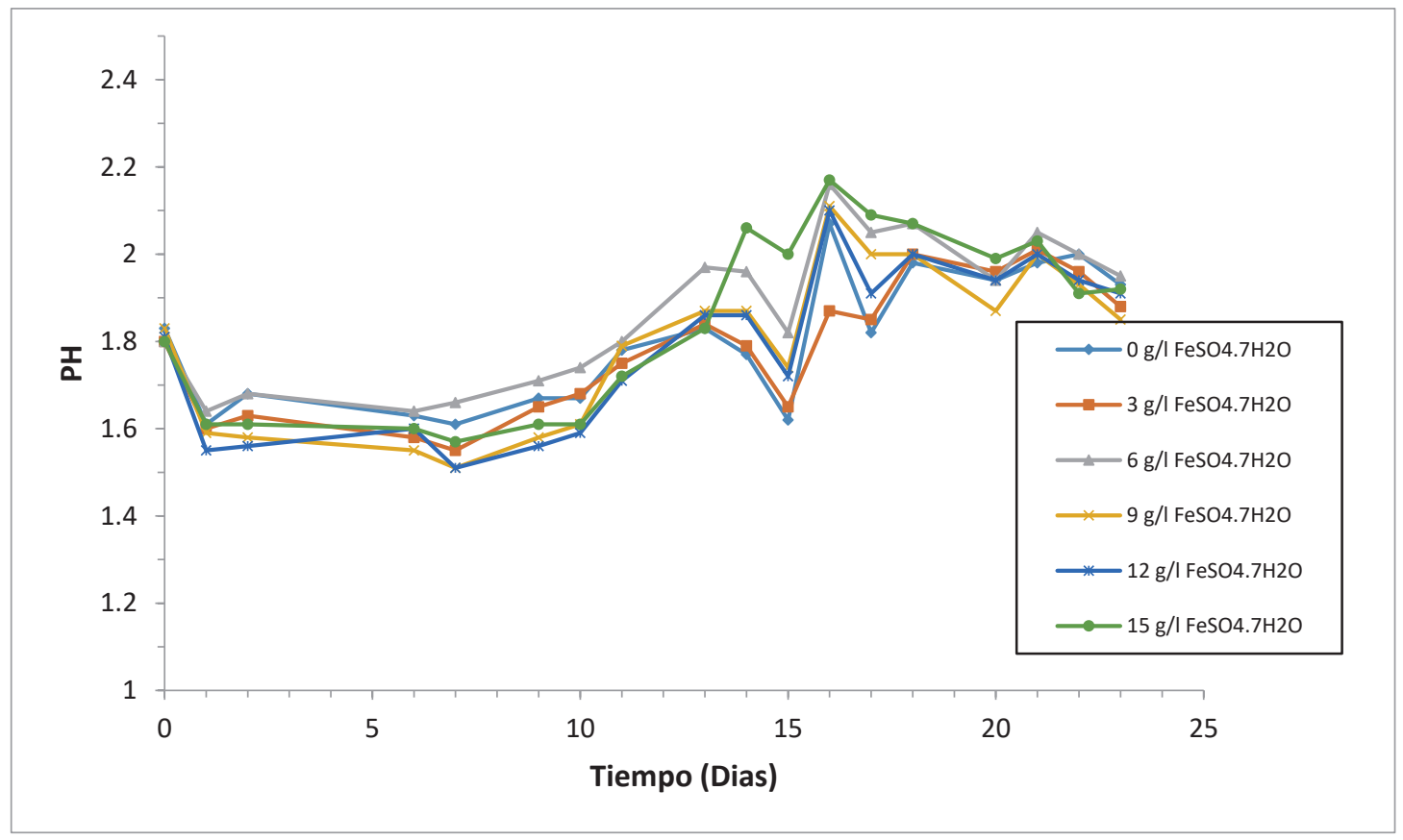

Figura 3. Variación del pH durante la primera etapa de biolixiviación.

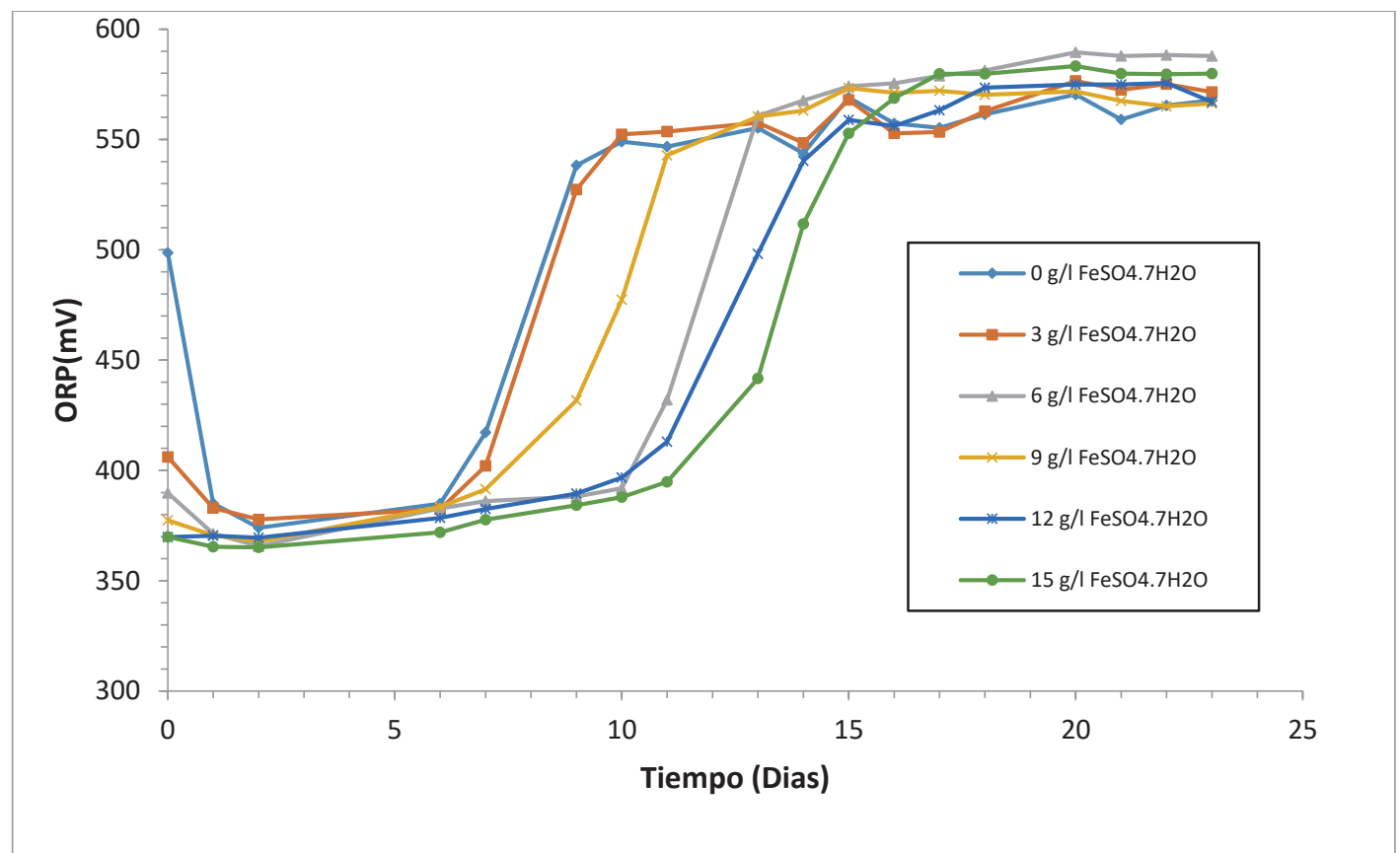

Figura 4. Medición de potencial de oxido-reducción (ORP), en la primera etapa del proceso de biolixiviación de un mineral sulfurado. 
concentración fue de $4.75 \times 10^{7} \mathrm{Cel} / \mathrm{mL}$. Se observa que las fases de adaptación y exponencial muestran la misma tendencia en todas las pruebas. La fase exponencial se inicia aproximadamente al día 8vo, consiguiéndose la máxima población bacteriana de $6.30 \times 10^{7} \mathrm{Cel} / \mathrm{mL}$, sin adición de $\mathrm{FeSO}_{4} \cdot 7 \mathrm{H}_{2} \mathrm{O}$, superior a la concentración del inóculo inicial en $42 \%$ comparado a la concentración de la primera etapa.

\subsubsection{Variación del $p H$}

$\mathrm{El} \mathrm{pH}$ de la solución se incrementa durante los primeros 7 días, posiblemente debido al incremento de la densidad de pulpa, siendo controlado con solución de ácido sulfúrico hasta recuperar su valor inicial. Por el transcurrir el tiempo se observa la disminución, siendo necesario su recuperación al valor inicial de 1.8

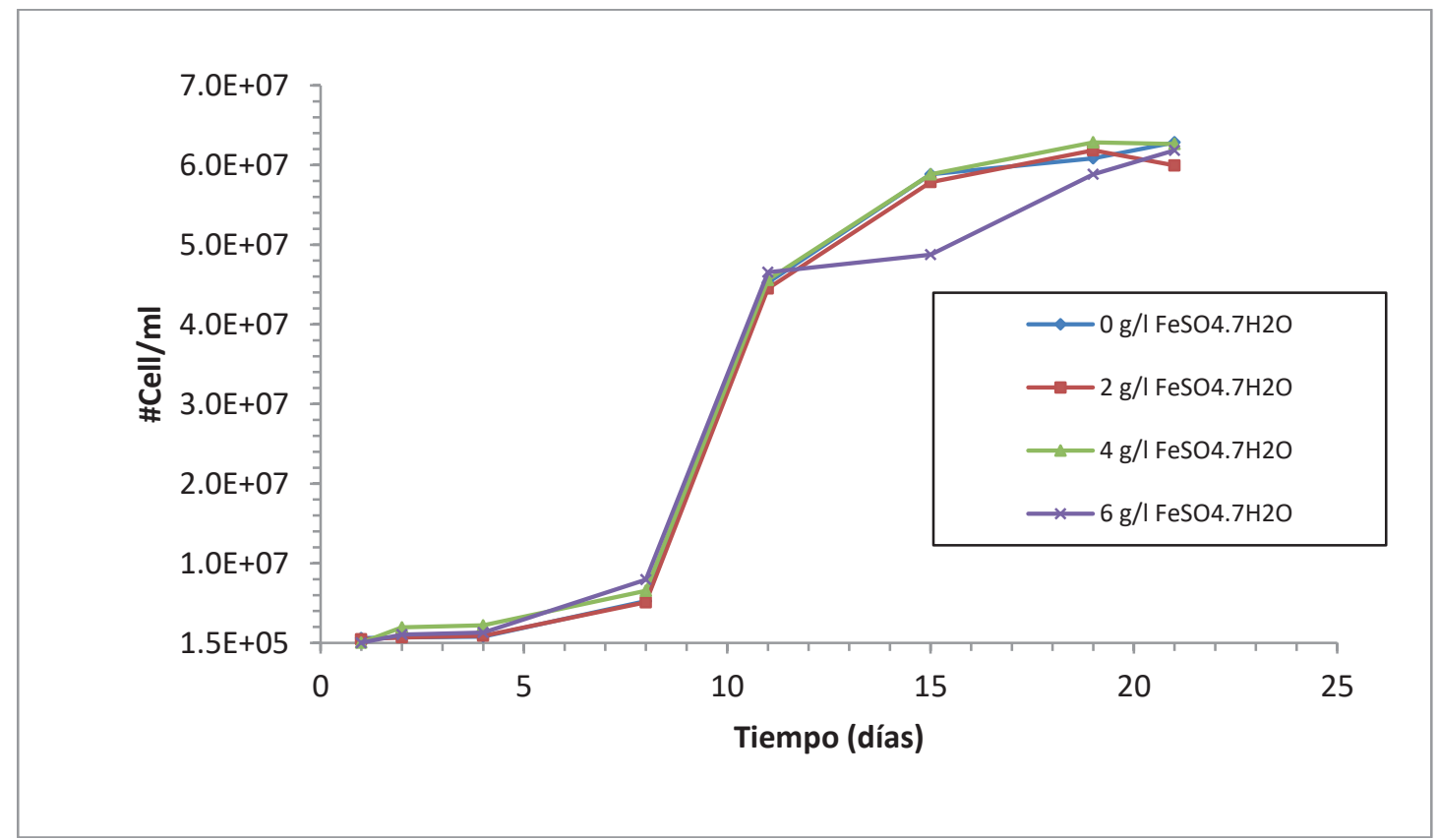

Figura 5. Variación de la población bacteriana durante la segunda etapa de biolixiviación de mineral sulfurado.

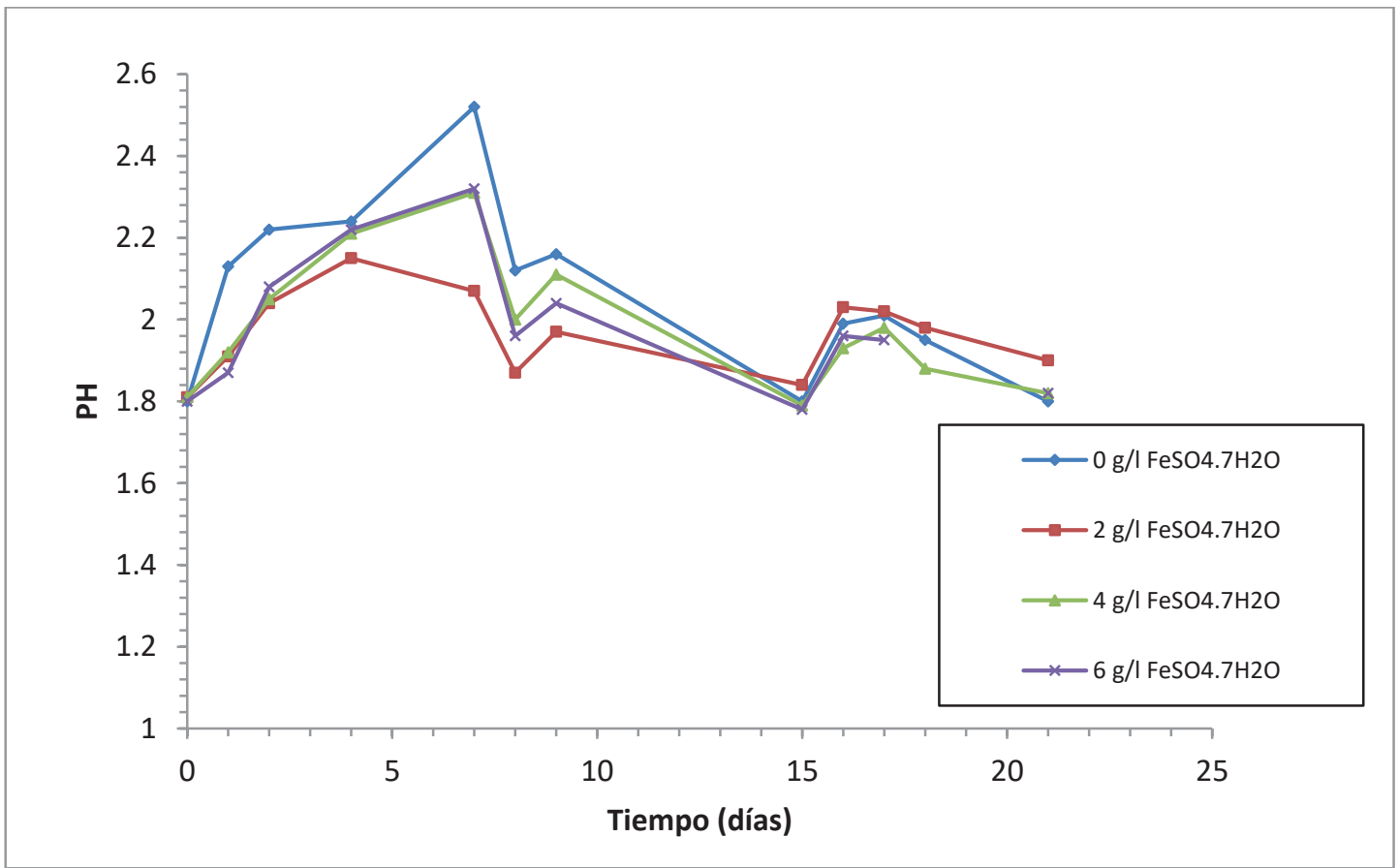

Figura 6. Variación del pH durante la segunda etapa de biolixiviación. 


\subsubsection{Medición del potencial de óxido-reducción}

En la Figura 7 se muestra el comportamiento del potencial de oxido-reducción de todas las pruebas. Logrando un máximo de $613.2 \mathrm{mV}$ con la menor cantidad de $\mathrm{FeSO}_{4} \cdot 7 \mathrm{H}_{2} \mathrm{O}$. También, se observa que alcanzan los 600 $\mathrm{mV}$ aproximadamente al 8vo. día.

\subsection{Tercera etapa de biolixiviación}

Se continua con el uso de solución de Medio 9k como sustrato de lixiviación, variando las concentraciones de $\mathrm{FeSO}_{4} 7 \mathrm{H}_{2} \mathrm{O}$. Para los ensayos se continúa utilizando frascos Erlenmeyer de $500 \mathrm{~mL}$, se agrega $6.0 \mathrm{~g}$ de mineral sulfurado $(2 \% \mathrm{~W} / \mathrm{V}), 30 \mathrm{~mL}$ de cepa bacteriana $(10 \% \mathrm{~V} / \mathrm{V})$ y $300 \mathrm{~mL}$ de sustrato $9 \mathrm{k}$ conteniendo $0.0,3.0,9.0$ y 15.0 $\mathrm{g} / \mathrm{L}$ de $\mathrm{FeSO}_{4} .7 \mathrm{H}_{2} \mathrm{O}$. El pH es regulado con solución de ácido sulfúrico. Se continuó el proceso en plataforma de agitación a $150 \mathrm{rpm}$. El inóculo es obtenido de la etapa anterior. Se efectúan controles de $\mathrm{pH}$, potencial de oxidoreducción y población bacteriana.

\subsubsection{Efecto en el crecimiento bacteriano}

A partir del inóculo el efluente de la segunda etapa, cuya población bacteriana fué de $6.30 \times 10^{7} \mathrm{Cel} / \mathrm{mL}$, lográndose el crecimiento exponencial aproximadamente después del

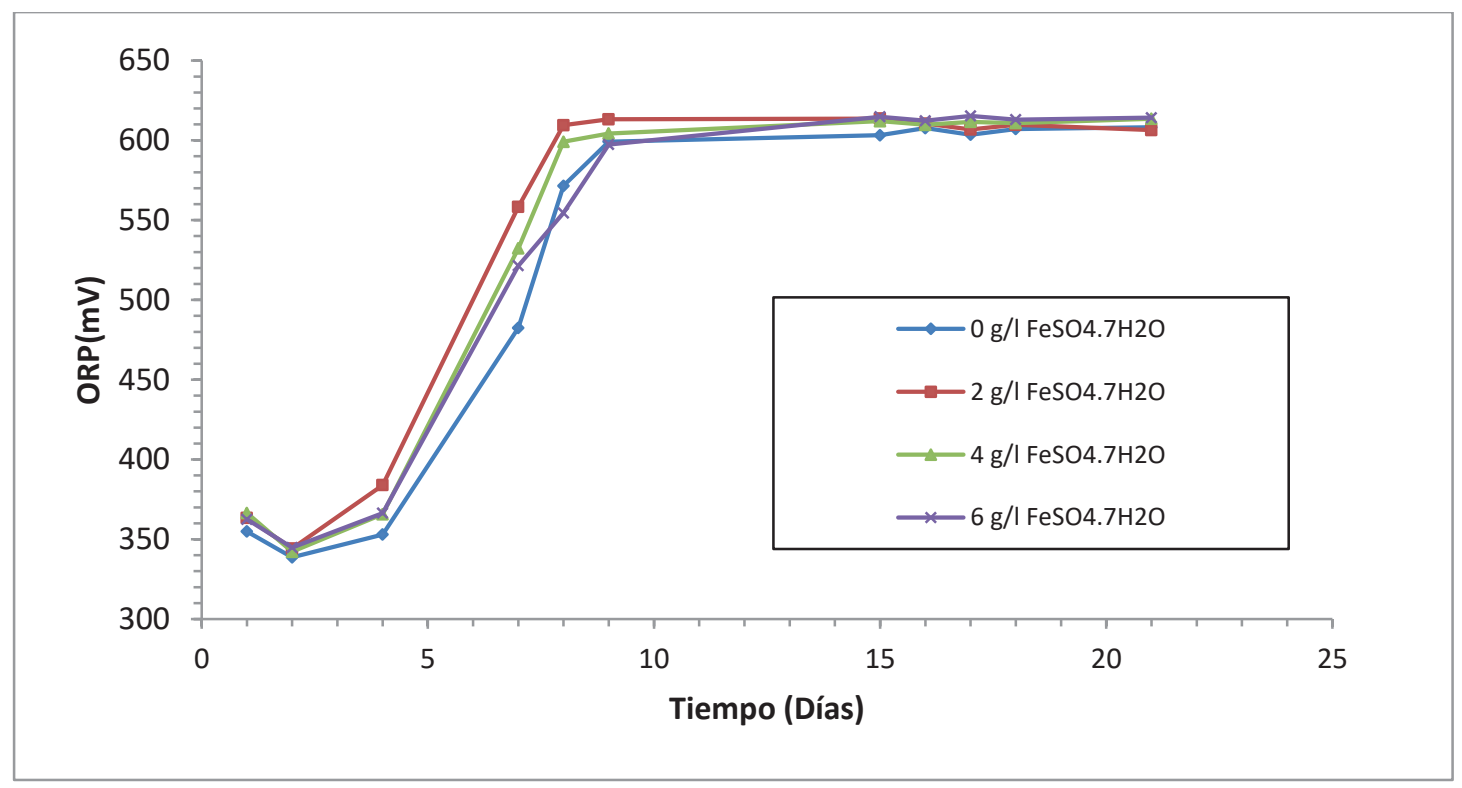

Figura 7. Medición de potencial de óxido-reducción (ORP), en la segunda etapa del proceso de biolixiviación de un mineral sulfurado.

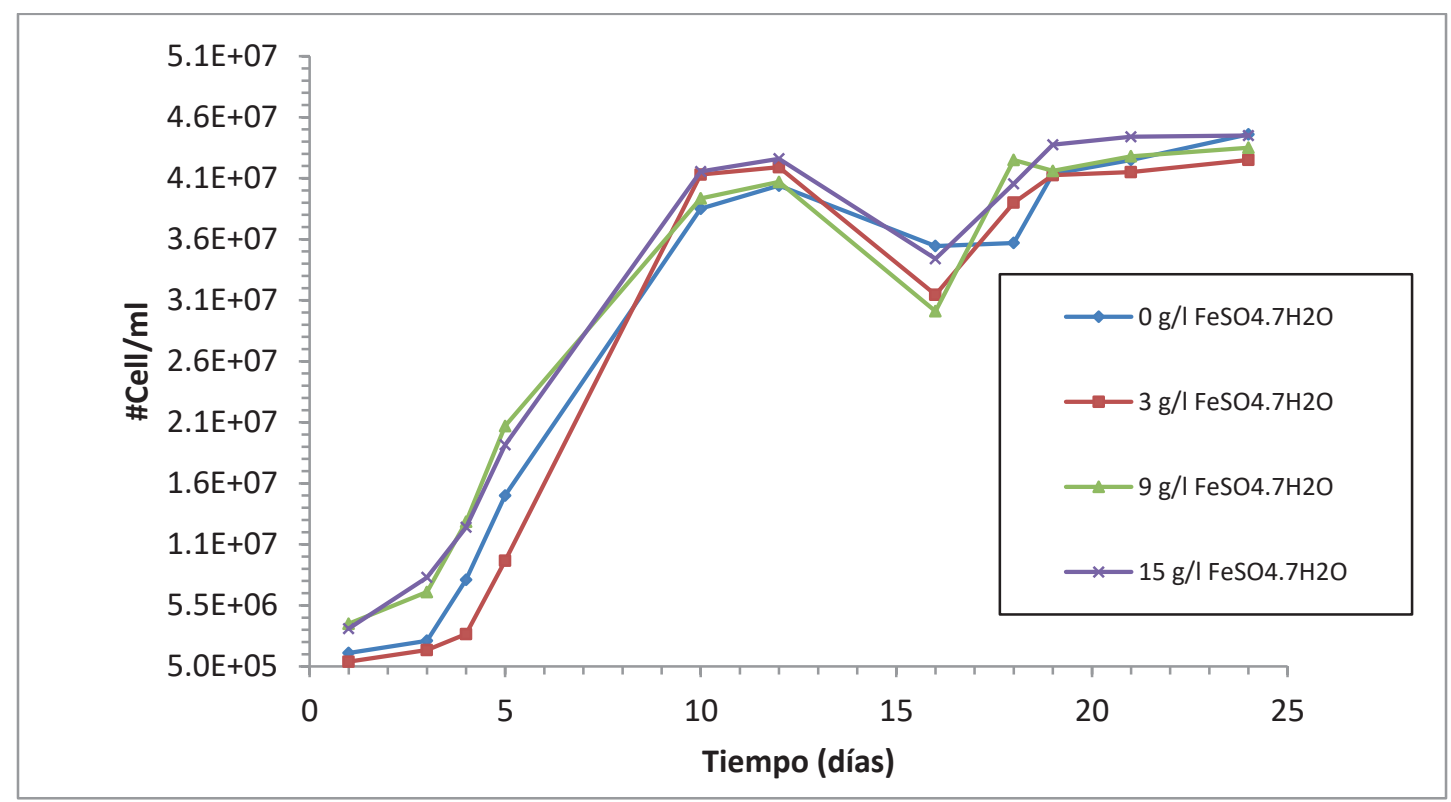

Figura 8. Crecimiento de la población bacteriana. Tercera etapa de procesamiento experimental. 
segundo día de iniciada la experimentación. A diferencia de la primera etapa, se logra reducir 8 días y comparado a la segunda etapa, en 5 días. El crecimiento exponencial finaliza aproximadamente a los 10 días. En esta etapa se logra mayor crecimiento $\left(4.51 \times 10^{7} \mathrm{Cel} / \mathrm{mL}\right)$ en la prueba que carece de la sal ferrosa. Se concluye que la adaptación $\mathrm{y}$ crecimiento bacteriano con provisión de mineral como medio proveedor de nutrientes es característica quimiolitotrófica de la bacteria Acidithiobacillus Ferrooxidans.

\subsubsection{Variación del $p H$}

Se observa incremento y disminución de $\mathrm{pH}$ en los tres primeros días. $\mathrm{La}$ solución con $15 \mathrm{~g} / \mathrm{L}$ de $\mathrm{FeSO}_{4} \cdot 7 \mathrm{H}_{2} \mathrm{O}$ alcanza un pH de 2.08, corrigiéndose con solución de ácido sulfúrico, luego se observa un incremento de la acidez llegando a un $\mathrm{pH}$ de 1.3 , posiblemente originado por la mayor cantidad de mineral, con respecto a la etapa anterior. En los siguientes 17 días aproximadamente, se controla el $\mathrm{pH}$, manteniendo alrededor de 1.8, seguidamente se observa una marcada disminución.

\subsubsection{Medición del potencial de óxido-reducción.}

Como se puede observar en la Figura 10, al cabo del tercer día se obtienen valores cercanos al máximo, manteniéndose casi constante durante el resto del periodo de prueba. A diferencia de la primera etapa, el crecimiento ocurre entre los días 7 al 15 aproximadamente y, en la segunda etapa, el

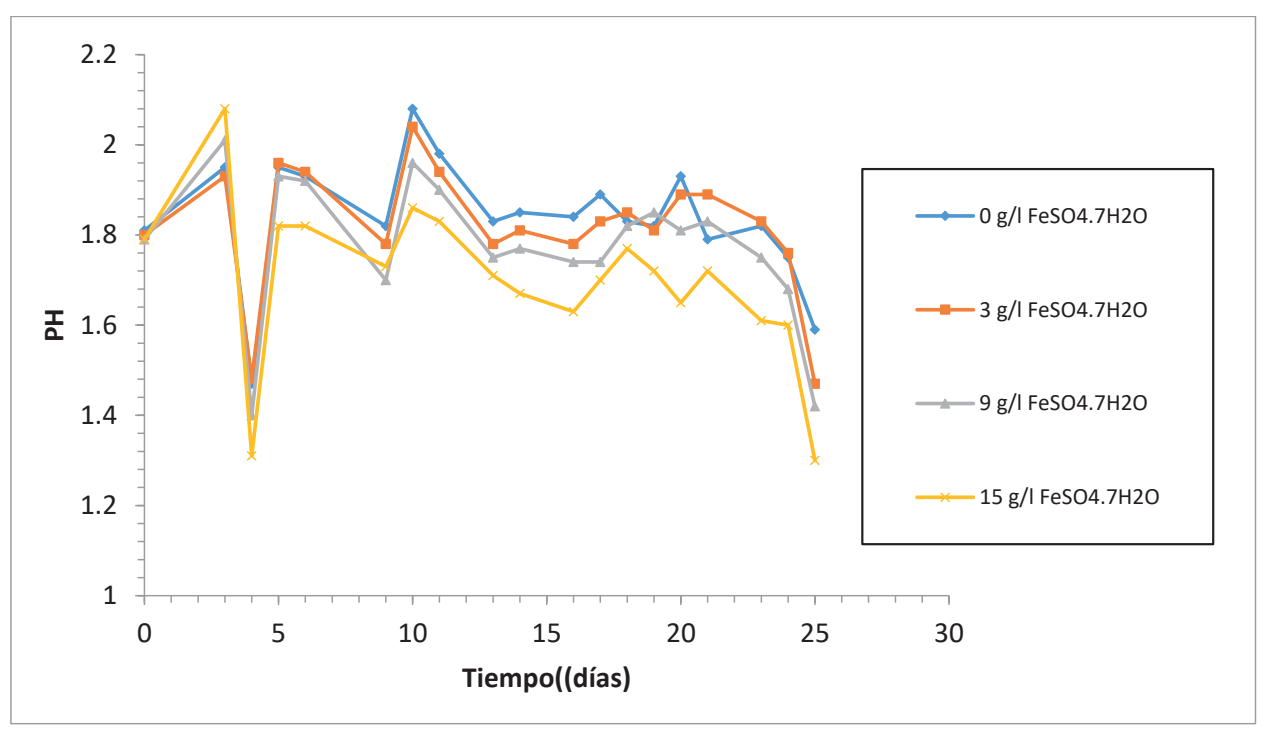

Figura 9. Variación del pH durante la tercera etapa de biolixiviación.

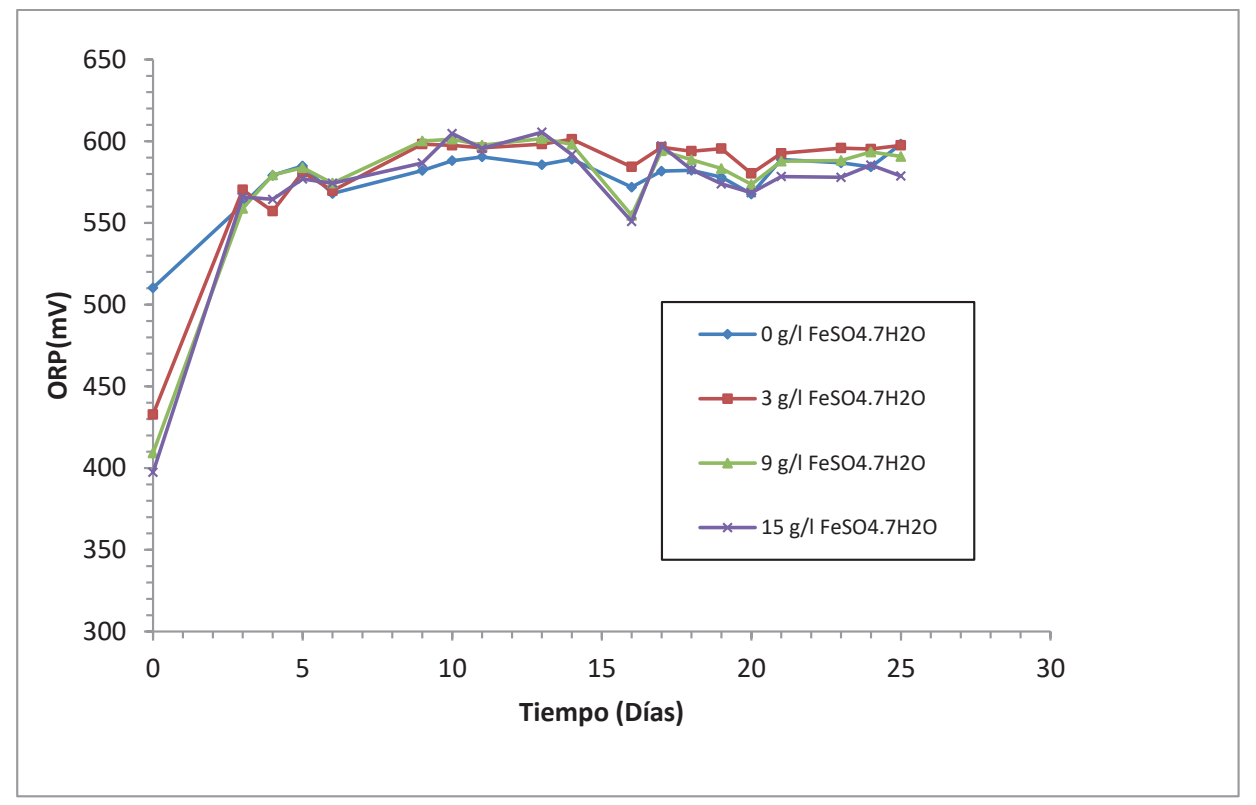

Figura 10. Medición del potencial de óxido-reducción (ORP), en la tercera etapa del proceso de biolixiviación de un mineral sulfurado. 
crecimiento ocurre entre los días 4 al 8, aproximadamente. En esta etapa, los valores máximos promedios oscilan alrededor de $585 \mathrm{mV}$ para cada uno de los ensayos.

\section{RESULTADOS}

En la primera etapa de la biolixiviación se logra un crecimiento poblacional aproximadamente en el periodo del 12vo. al 24vo. día, seguido de un quiebre y con tendencia a mantenerse constante durante el periodo de duración de la etapa. La mayor población bacteriana fue de $4.75 \times 10^{7} \mathrm{Cel} / \mathrm{mL}$ después de 24 días, con sustrato de 6.0 $\mathrm{g} / \mathrm{L}$ de $\mathrm{FeSO}_{4} .7 \mathrm{H}_{2} \mathrm{O}$ y llegando a tan solo $67 \%$ del inóculo inicial. Mientras que el potencial de óxido-reducción muestra un comportamiento variado en el periodo de crecimiento. En los primeros 6 días, la muestra sin la sal ferrosa, se incrementa de $360 \mathrm{mV}$ a $585 \mathrm{mV}$ al $10 \mathrm{mo}$. aproximadamente. La muestra de $15 \mathrm{~g} / \mathrm{L}$ de $\mathrm{FeSO}_{4} .7 \mathrm{H}_{2} \mathrm{O}$ tiene un incremento retardado, pero llega a un máximo de $560 \mathrm{mV}$. Las restantes, en promedio alcanzan $575 \mathrm{mV}$.

En la segunda etapa la cepa inoculada tuvo una concentración de $4.75 \times 10^{7} \mathrm{Cel} / \mathrm{mL}$, se observó las fases de adaptación y crecimiento tienen la misma tendencia de crecimiento en todas las pruebas; la fase exponencial se inicia al octavo día, llegando a un máximo de $6.30 \times 10^{7}$ $\mathrm{Cel} / \mathrm{mL}$ con $0.0 \mathrm{~g} / \mathrm{L}$ de $\mathrm{FeSO}_{4} \cdot 7 \mathrm{H}_{2} \mathrm{O}$. La concentración bacteriana es superior en $42 \%$ en relación al inóculo y el valor máximo de potencial de oxido-reducción de 613.2 $\mathrm{mV}$. En el ensayo con $2 \mathrm{~g} / \mathrm{L}$ de $\mathrm{FeSO}_{4} 7 \mathrm{H}_{2} \mathrm{O}$ se observa que supera a $600 \mathrm{mV}$.

En la tercera etapa, el inicio del crecimiento exponencial se da al tercer día de iniciada la biolixiviación, se reduce 9 días en comparación a la primera etapa y, en comparación a la segunda etapa, 5 días. El crecimiento exponencial finaliza aproximadamente después de 10 días. En esta etapa se observa que, con ausencia de la sal ferrosa, se logra la concentración de $4.51 \times 10^{7} \mathrm{Cel} / \mathrm{mL}$; con cierta similitud, que en otras concentraciones de la sal de hierro. Se observa una marcada evolución de valores de ORP durante los 3 primeros días, y luego con tendencia a mantenerse constante durante todo el periodo de ensayo con valor promedio a $585 \mathrm{mV}, 15 \mathrm{mV}$ menor que en la segunda etapa y $10 \mathrm{mV}$ más, en comparación a la primera etapa.

Comparado a la primera etapa ello ocurre entre los días 7 al 15 aproximadamente, y en comparación a la segunda etapa, ocurre entre los días 4 al 8. En la tercera etapa, después de los 3 días, los valores se mantienen altos durante el resto del periodo de ensayo. Finalmente, comparado a la primera etapa, ésta se da entre los días 7 al 15 aproximadamente y en comparación a la segunda etapa, se dio entre los días 4 al 8, aproximadamente.

El potencial redox como factor determinante del crecimiento y del metabolismo del cultivo, nos indica su capacidad para aceptar o donar electrones, o sea las características oxidantes o reductoras de los componentes del medio o sustrato determinada en parte por la concentración de oxígeno. Estas características oxidantes son las que requieren las bacterias del género thiobacillus, favoreciendo su crecimiento y el desarrollo de un metabolismo oxidativo.

También, el potencial redox indica las actividades metabólicas de los microorganismos vivos y puede ser utilizado para especificar el ambiente en que los microorganismos son capaces de generar energía y sintetizar sus enzimas o generar nuevas células sin recurrir al oxígeno molecular.

Los diversos estados de oxidación del azufre $(-2,2$, 4 y 6) propician un potencial redox y la obtención de una gran variedad de enzimas que pueden oxidar diferentes compuestos inorgánicos de azufre, razón por la cual, es recomendable su identificación, así como también las rutas metabólicas, permitiendo optimizar las condiciones de las reacciones de sulfooxidación y mejorar la actividad catalítica bacteriana.

La medición del potencial (Ev) es la disolución del dador de electrones y por otro lado el receptor de electrones a concentraciones variadas de sustrato a $\mathrm{pH}$ 1.8 y a $22{ }^{\circ} \mathrm{C}$, mostrando valores cada vez más positivos debido a la tendencia creciente de aceptar electrones con la consiguiente formación de sulfatos.

\section{CONCLUSIONES}

El potencial de óxido reducción ofrece muchas ventajas en el monitoreo en tiempo real y registro de potenciales de medios en bioprocesos.

Las cepas bacterianas son adaptadas satisfactoriamente en distintos medios conteniendo cantidades variadas de hierro como sulfurados y óxidos, provenientes de canteras de alta mineralización (presencia de cobre, plomo, zinc, azufre, sílice, oro, plata y otros). Sin embargo, la determinación cualitativa y cuantitativa sigue siendo materia de investigación en función a la constitución del sustrato proveído.

Los iones simples y compuestos; aunados al consorcio bacteriano transfieren los electrones provenientes de la oxidación de materia inorgánica a los aceptadores de electrones disponibles de carácter más oxidante, permitiendo obtener el mayor margen de ganancia energética para la oxidación del substrato mineral inorgánico presente, de los que se proveen el carbono necesario y energía para su evolución, siendo un mecanismo propio de organismos quimiolitótrofos.

El estudio abordado nos ha permitido incrementar los conocimientos y difundir los resultados con miras de su uso o replicación aplicada al tratamiento de materiales y efluentes industriales.

\section{AGRADECIMIENTOS}

Los autores agradecen a la dirección del Vicerrectorado de Investigación, que, a través del Consejo Superior de Investigaciones, se financió la ejecución del proyecto C17162131 del Grupo de Investigación; así mismo, a los estudiantes y docentes de las Facultades de Ciencias 
Biológicas y Química e Ingeniería Química, que participaron para la obtención de los objetivos.

\section{REFERENCIAS}

Acevedo, F., Gentina, J. (2005). Fundamentos y Perspectivas de las Tecnologías Biomineras. Archivos de Ingeniería Bioquímica, 3-24. http://www.euv.cl/publicaciones/series_ libros_nuevos/fundamentos_biomineras.htm

Alvarez, M. (2009). Microbial treatment of heavy metal leachates. Spain: Graficas Terrasa. Department of Biotechnology, Lund University. https://lup.lub.lu.se/search/publication/24654

Arias, V., Lovera, D., Quiñones, J., Flores, A., Gil, J., Ramírez, L., \& Cayo, H. (2015). Biolixiviación de cobre a partir de minerales sulfurados con altos tenores de pirita y arsenopirita. Revista Del Instituto de Investigación de La Facultad de Ingeniería Geológica, Minera, Metalurgica y Geográfica, 18(36). https://revistasinvestigacion.unmsm. edu.pe/index.php/iigeo/article/view/12164

Barton, L. L., Mandl, M., \& Loy, A. (2010). Geomicrobiology: Molecular and environmental perspective. In Geomicrobiology: Molecular and Environmental Perspective. https://doi.org/10.1007/978-90-481-9204-5

Donati, E. R., \& Sand, W. (2007). Microbial processing of metal sulfides. In Microbial Processing of Metal Sulfides. https:// doi.org/10.1007/1-4020-5589-7

Espinoza, J., Revah, S., \& Le Borgne, S. (2010). Rutas metabólicas de oxidación del azufre en bacterias quimiolitoautótrofas, relevancia ambiental y biotecnología. Mensaje Bioquímico, XXXIV, 101-120. http://bq.unam.mx/mensajebioquimico

Fagundo C., J. R., González H., P., Suárez M., M., \& Melián R., C. (2005). Relaciones entre potenciales redox $\mathrm{y}$ concentraciones de sulfuros en aguas termales de Cuba. Contribución a La Educación y La Protección Ambiental, 6(March 2015), 3-15. https://www. researchgate.net/profile/Patricia-Gonzalez-Hernandez/ publication/237708654 RELACIONES ENTRE POTENCIALES REDOX ${ }^{-} \mathrm{Y}_{\text {CONCENTRACIONES }}^{-}$ DE SULFUROS EN AGUAS TERMALES DE CUBA/ lin $\overline{\mathrm{k}} \mathrm{s} / 5507 \mathrm{c} 74 \mathrm{a} 0 \mathrm{cf} \overline{2} \mathrm{~d} 7 \mathrm{a} 281 \overline{2} 65237 / \mathrm{RELAC} \overline{\mathrm{ION}}$ ENTRE-POTENCIALES-REDOX-Y-CONCENTRA
Kaksonen, A. H., Plumb, J. J., Franzmann, P. D., \& Puhakka, J. A. (2004). Simple organic electron donors support diverse sulfate-reducing communities in fluidized-bed reactors treating acidic metal- and sulfate-containing wastewater. FEMS Microbiology Ecology, 47(3), 279-289. https://doi. org/10.1016/S0168-6496(03)00284-8

Ospina, J. D., Mejía Restrepo, E., Osorno Bedoya, L., Márquez, M. A., \& Morales, A. L. (2012). Biooxidación de concentrados de arsenopirita por Acidithiobacillus ferrooxidans en erlenmeyer agitados. Revista Colombiana de Biotecnología, $X I V(1), \quad 135-145 . \quad$ https://revistas.unal.edu.co/index.php/ biotecnologia/article/view/31851\#textoCompletoHTML

Pradhan, N., Nathsarma, K. C., Srinivasa Rao, K., Sukla, L. B., \& Mishra, B. K. (2008). Heap bioleaching of chalcopyrite: A review. In Minerals Engineering (Vol. 21, Issue 5, pp. 355365). https://doi.org/10.1016/j.mineng.2007.10.018

Rawlings, D. E. (2005). Characteristics and adaptability of ironand sulfur-oxidizing microorganisms used for the recovery of metals from minerals and their concentrates. In Microbial Cell Factories (Vol. 4). https://doi.org/10.1186/1475-28594-13

Rivera, R., Camejo, P., Moya, F., López, J., \& Munguía, M. (2011). Estudio de biolixiviación de un mineral de sulfuros de un mineral de sulfuros de cobre de baja ley con bacterias Tio- y Ferro-oxidantes en condiciones termófilas. Revista de La Facultad de Ingenieria, 26, 65-73. http://www. revistaingenieria.uda.cl/Publicaciones/260009.pdf

Sand, W., Gerke, T., Hallmann, R., \& Schippers, A. (1995). Sulfur chemistry, biofilm, and the (in)direct attack mechanism - a critical evaluation of bacterial leaching. Applied Microbiology and Biotechnology, 43(6), 961-966. https:// doi.org/10.1007/BF00166909

Wang, J., Zhu, S., Zhang, Y. S., Zhao, H. B., Hu, M. H., Yang, C. R., Qin, W. Q., \& Qiu, G. Z. (2014). Bioleaching of lowgrade copper sulfide ores by Acidithiobacillus ferrooxidans and Acidithiobacillus thiooxidans. Journal of Central South University, 21(2), 728-734. https://doi.org/10.1007/s11771014-1995-3 